\title{
Consensus Building: Implications for Labour - Management Relations in Nigeria
}

\author{
Samuel Emeka Mbah (Corresponding author) \\ Department of Industrial Relations and Personnel Management \\ University of Lagos, Akoka, Yaba, Lagos, Nigeria \\ E-mail: mbasam2011@yahoo.com
}

Iwuji Innocent Ifeanyi

Department of Business Administration

University of Lagos, Akoka, Yaba, Lagos, Nigeria

E-mail: iwujiifeanyi@yahoo.co.uk

Received: December 17, 2011 Accepted: February 6, 2012 Published: March 1, 2012

doi:10.5539/jms.v2n1p190 URL: http://dx.doi.org/10.5539/jms.v2n1p190

\begin{abstract}
This paper adopts a qualitative approach to describing the concepts of consensus building in labour and management relations in the industry. Labour management relations in Nigeria are often described as a soar relationship. This is because labour - management views are seen as diametrically opposed to each other. The relevant stakeholders have failed in their responsibility to ensure that industrial peace and harmony reigns. Rather, they prefer conflicts and strikes as the only veritable means to actualize their desired needs. Consequently in this soar relationship, there is disobedience, incessant breakdown of law and order, man - hour - loss, state of job insecurity and so on. So in order to reduce to the barest minimum these occurrences, there is the need for consensus building among relevant stakeholders in industries. This will help ensure long awaited industrial peace and harmony needed for industrial growth and economic development. Authors therefore used the, consensus theory, which is a sociological perspective model, by Thomas Kilmann (1974), a conflict - handling model to explain the tenets and managerial implications of consensus building. The fifteen step decision making process credited to Barbara Gray was recommended for implementation of consensus building. Finally, the paper concludes that in spite of the conflictual nature of people in industry, conflict accommodation, collaboration, problem - solving mode remain best and effective consensus building strategies when fully implemented. The methods of data collection include textbooks, journal articles, newspapers, and internet source.
\end{abstract}

Keywords: Conflicts, Consensus building, Accommodation, Collaboration, Compromising

\section{Introduction}

There is an increasing need for consensus building in our today's 'mechanical Newtonian world' that is characterized by political fragmentation, shared power and conflicting values. The business or workplace environment is dynamic and competitive. For this reason, labour relations activities in work organizations require therefore a constant review in order to ensure that they survive this competitive nature and to achieve the purpose for which they have been established. In the same way, there is obvious need for organizations to develop innovations and strategies that ought to correspond or fit this dynamic nature of workplace or business environment. One of such innovations or strategies is the institution of consensus building in ensuring good quality labour management relations in our industries.

From the industrial relations perspective, consensus building is a conflict-management mechanism which focuses on collaborative engagement among relevant stakeholders in industry. It is also known as collaborative problem-solving strategy.

For the purpose of efficient and effective operation of business, some industrial relations innovations stress labour-management relations as one of the ways to promote consensus or cooperative or joint governance 
relationships in work organizations.

Kay and Paul (1976) have identified other ways to include: principled negotiation which is rightly referred to as collective bargaining, employee centred management, employee involvement, quality of working life, innovative work practices, the high-performance workplace, learning organizations among others.

The importance of any innovation within the context of work organization is to improve labour-management relations, increase organizational performance and at the same time to provide the increased job satisfaction on the part of workers (Fox, 1972).

Consensus building therefore is an emerging trend in the field of industrial relations. It is a concept as well as an approach. As a concept it advocates and envisages a completely conflict free labour-management relations as a permanent feature in work organizations. But as an approach, consensus is viewed as a process or means of enhancing problems solving situations in organizations.

Webster reference dictionary has defined consensus to mean concord of opinion, authority testimony or agreement. In Latin maxim, "consensus ad idem" means the meeting of the minds which invariably means or implies agreement (Achike, 1981).

The concept of consensus in industrial relations is predicated on mutual partnering relationship or a strategic alliance between two or more parties (Alexander, 1978). It denotes unity, equilibrium or balance of interests in labour-management relations.

In view of the above, consensus building can be defined as a process that is typically designed either to advance shared vision or to resolve a conflict which usually results in an exchange of information or a joint agreement or commitment to actions between labour and management or between two or more parties, such as work organizations.

Collective bargaining or negotiation is an instrument for consensus building in work organizations. Fajana (2006: 31), remarks, intra- organizational bargaining is designed to effect consensus within the industrial negotiating parties; usually the outcome of any bargaining situation is either, agreement or disagreement. Fajana further states that disagreements occurs when for instance, the consensus on basic bargaining issues and values no longer prevail, and the parties on the bargaining table resume their conflict orientation, whenever this occurs, consensus is disrupted and conflict takes over the stage. The implication is that labour- management relationship is greatly associated with conflicts of interests and values.

Workers and management are diametrically opposed to each other in various ways especially on issues that concern them. Watson (1987) explains that conflict and co-operation are omnipresent and inevitably co-exist between workers and employers, that co-operation with one interest group may automatically imply conflict with another. Conflictual activities are as much part of worker life as well as co-operation. Conflict and co-operation therefore are two sides of the same coin. The extent to which each can be evaluated or judged as good or bad or healthy will depend on the ends to which each is related.

The main goal of consensus is to seek for a balance of interests and to maintain cooperative labour- management relations. If this is not feasible, conflict may ensue as a remedial and natural phenomenon (Fox, 1972). To this, Fajana (2006:30) remarks: "the occasion after agreement is struck on the negotiating table, the parties one in the next moment apt to look for issues in the agreement that requires review. On such occasions, the systems equilibrium is disrupted, the preconditions for the parties' readiness to resolve problems on the basis of joint regulation would no longer be fulfilled", depicting that existing equilibrium has been misbalanced and a situation of conflict has taken over.

Adejumo (2011) laments the destructive effects of strikes on organizational growth and development and that of the country at large. Adejumo, further states that the inevitability of workplace conflict makes it compelling that strategy to manage disputes be developed and sustained at the plant or organizational levels. According to him, conflict is not the problem but the real problem is inability or lack of capacity to manage conflict in a way that can result in productive outcome. The inevitability of conflict in industries requires that a virile mechanism and process be institutionalized in industries to cater for these disruptive elements against industrial peace and harmony. It has always been the labour that initiates moves for peace. This is true when we consider the upper hand that management takes in the scheme of things in industries. But this effort of labour is often dashed. Severally, collective bargaining has not resulted in productive outcome either because the process is defaulted or agreements reached are not implemented. This is the reason why it has become absolutely necessary for industries to truly develop consensus building strategies that enhance stable labour management relations so that these interventions may be minimized if not completely eradicated. 
The recent nationwide strike triggered by oil subsidy removal in Nigeria is a good example of how the mismanagement of conflict, arising among stake-holders (government, labour, management and civil societies) can result into a colossal waste of resources, which could have been channeled to development of infrastructure. Nigeria lost N733 billion ( $\$ 4.7$ billion) in the one week strike, excluding loss of lives and valuable property. The current strike by the Academic Staff Union of Nigerian Universities (ASUU) was triggered by the failure on the part of government to honor the 2009 agreement with ASUU on retirement age and funding of Universities. The above strikes are in no way isolated but rather a recurring situation in the Nigerian post independence era. Given the above background and the colossal waste of resources engendered by incessant strikes and lockouts the study addresses the following questions: What factors are responsible for industrial unrest in work situations? What are the prerequisites of effective collaboration or consensus building? What methodologies can be employed in creating collaborative work organizations? What policy changes are to be put in place to guarantee sustainable industrial peace and harmony in work organizations and improved socio-economic conditions of the country in general?

The aim and objective of this paper therefore is to examine theoretically the need for consensus building as a tool or strategy for quality labour and management relations and to exemplify the willingness of both the labour and management to resolve conflicting issues that relate to casual and economic factors which often times disrupt industrial peace and harmony.

To achieve these objectives authors employed desk research method that made great use of literature materials from text books, relevant journal articles, newspaper publications, excerpts from papers, internet source among others.

The paper is structured as follows: section 2 deals with literature review including theoretical foundation and supporting evidence. Section 3 presents Barbara Gray's methodology for Consensus Building implementation. In Section 4 we discuss Implications for Labour - Management Relations followed by Conclusion in section 5.

\section{Literature review}

This section explores the various theories upon which the study is grounded as well as the supporting evidences based on real world situations.

\subsection{Theoretical foundations}

Consensus theory is a sociological frame of thought which borders on making use of culture and socialization as twin concepts involved in the explanation of social life (Haralambos 1980).

The consensus theory sees culture as social heritage. That is those learned behavior in any society like, ideas, techniques, habits etc, which are passed on by one generation to another. These ideas, techniques and or habits are virtually a set of solutions to problems that in the course of time people have met and solved before. This learned behavior or social inheritance of any society is called its culture.

Through the process of socialization culture is internalized and values imbibed. What this implies is that those ideas, techniques, habits including values and aspirations of the people become part of their behavior which can unconsciously be exhibited at appropriate time and circumstances that may demand for them.

Internalized cultural rules means that those rules and expectations that make up the culture have been accepted by the people and can be used to determine how the people should act especially in workplace situation. In the workplace these ideas, values, aspirations, or techniques transform into workers attitude which must have to agree with work rules, otherwise will result into conflict. It follows therefore that work life of the people in industry is determined by obedience or compliance to the organizational culture which is made up of ideas, expectations, values, rules which prevail in the industry. The extent to which workers and management maintain peace and harmony in industry is a function of or level of consensus which exist between them.

\subsubsection{Thomas Kilmann model of consensus building}

Another possible and effective approach towards consensus building is by adopting the Thomas Kilmann (1974) model on conflict management which stem from the work of (Blake \& Morton1964). The Thomas Kilmann (1974) two- dimensional model which was a modification from (Blake and Morton, 1964) is based on five conflict management approaches namely competing, collaborating, compromising, avoiding and accommodating. Akanji (2010) identifies these two-dimensions as:

Assertiveness: This implies the tendency of one becoming self - centred or a feeling of personal concern more than that of others. It means to satisfy ones needs at the detriment of others. The second is cooperativeness; which means that an individual has concern for himself and for others ,thus, the individual is willing to get the conflict 
resolved in a manner that the interests of both parties in conflict would be satisfied. According to Akanji (2010), it is these two dimensions (assertiveness and cooperativeness) of a person's conflict behavior that were used to describe the five conflict handling behaviours as represented in a schematic diagram in figure 1.

Consensus building relates more with Thomas Kilmann Model in Accommodating, collaborating, and compromising as various forms of conflict handling behaviours. Accommodating here means to play down the difference between the parties to a conflict and focusing on commonality in order to satisfy the interest of the other party. In such situation individuals attitudes reflect charity, selflessness, obedience to one another and yielding to please the partner, thus passively accepting the decisions the partner makes (Akanji, 2010), implying that individuals are both unassertive and cooperative.

The next is collaborating; this relates to parties who have more and high concern for self and for others. The individuals are more assertive and cooperative. This is popularly called joint- problem solving mode. Akanji (2010) explains that joint problem - solving in essence is an approach whereby the parties listen to each other, discuss the issues together, understand the conflict and attack the issues. This can be achieved by the parties themselves or by intervention of a third party. There is earnest show of respect regardless of who is right or wrong. This method has received a very wide approval among apologists of this method because of its vintage position in achievement of goals and in proffering solutions to problems. This can as well lead to win- win situations.

Third one is sharing or compromising. This means the spirit of give and take or sharing. It is defined as involving an expedient, neutrally acceptable solution which partially satisfies both sides (Akanji, 2010). He further states that it may mean splitting the difference exchanging concessions, or seeking a quick middle- ground position. It is very unique because it represents the midpoint in the dimensions of production oriented versus people orientation. This means that individuals with this style exhibit more than the basic knowledge or skills in both assertiveness and cooperativeness, hence the approach is seen as not extremely effective but is middle point appropriate.

This paper is anchored therefore on the tenets of consensus theory perspective as well as the conflict handling model by (Thomas Kilmann, 1974) which actually illuminate better understanding on best approach to develop and institutionalize consensus building and enhance a stable labour-management relation in industry. What then will constitute the available mechanisms for consensus building in workplace situation?

\subsubsection{Mechanisms available for consensus building}

Consensus building occupies a vintage position in labour- management relations especially in terms of avoidance of conflict. In labour-management relations, conflict is inevitable but in the midst of conflict there is a challenging need to restore peaceful and harmonious work relationship through the consensus of labour and management. Obisi. (1996) asks, if two can work together except if they agree? Obisi's observation is a simple illustration that agreement remains essential ingredient for labour-management relations. Since there can never be a conflict free economy or organization, it follows that efforts have to be made by both labour and management to reduce to the barest minimum tendencies that are capable of generating conflicts and to achieve this motive, there is the need to put in place consensus building mechanisms that will ameliorate these inevitable conflict relationship between labour and management. Some of these machineries as identified in (Kay \& Paul 1976) include: Principled Negotiation, Employee Centred Management and Involvement, Collective Bargaining, Joint Consultation, Quality of Working life, Innovative work practices, High-Performance Workplace and Learning Organization among others. We briefly examine how each of them operates as consensus building factor in the work industries.

Principled Negotiation: This simply refers to initiating a discussion between the workers and management on some issues involving guided bargaining. The resultant cooperation in the negotiation is concord of opinion, and a manifestation of consensus or agreement in labour- management relations.

Employee Centred Management and Involvement: These are processes providing employees with the opportunity to influence decision - making on matters which affect them. As the workers' voice has been suppressed and not heard, any attempt by the worker to regain freedom from the exploitation which defines their interactions is resisted by management, and because of this, conflicts occur frequently as the only measure to advance or manifest workers' discontentment. Employee centred management and involvement therefore are processes adopted in work organizations which provide employees with the opportunity to influence decisionmaking on matters which affect them. They act as consensus building mechanism which allows the worker the freedom of enterprise in decision-making and a leverage for management in formulating policies and program that are employee centred. This will not only create peaceful and harmonious co-existence but it will also improve productivity and organizational development.

Collective Bargaining: This is a direct negotiation between trade unions and employers. The term is generally 
used for the settlement of wage claims and improvement in the working conditions of all workers of a union or of several unions by a collective agreement. The organization into trade unions of workers within the same trade gives the union power to meet the employers with unified demands and excludes local individual bargaining, a contract of collective agreement between them ensues which ameliorates any form of conflict and create room for the accommodation of divergent views of both labour and management.

Joint Consultation: This mechanism is the involvement of employee representatives in discussion and consideration of matters which affect them. The concern of a joint- consultation in workplace is on matters of common interest which are not items for negotiation. This is referred to in industrial relations parlance as jointconsultative council (JCC) or put in another way joint problem- solving group. Beach (1975) describes it as union-management cooperation which is the same as consensus.

Innovative Work Practices: The desire of every individual worker in any organization is to achieve results, grow, have job satisfaction etc and the employer in turn wants the worker in terms of commitment to work. One of possible ways to achieve innovative work practices and policies is through making the job more challenging by enlarging and enriching the job content. As the worker sees the challenging tasks he becomes more committed to higher performance and as the worker tries to achieve this fit, he desires more satisfaction on the job and this brings about industrial peace harmony within the organization.

High Performance Workplace: High performance workplace which essentially is a function of organizational pay package or reward system or pay and performance management in more acceptable term is a variable of consensus building between labour and management in the industry. Pay is a motivating factor of performance and if the employee does not receive adequate pay for adequate performance, he becomes embittered and less committed. Less workers' commitment manifest in various negative attitudes to work such as absenteeism, lateness, malingering, excessive excuses, long hours in toilet and so on. The implications of these are unhealthy labour management relations and in order to avert these unwanted attitudes, employers and management resort to motivation of the workers by instituting a reward system that can encourage workers to high performance practices. Through this mechanism or strategy, consensus, confidence and commitment will be restored at the workplace.

Learning Organization: There is need to build a motivated and highly skilled workforce who is seeking a career that combines skills with knowledge of their organizations. To this, organizations strive continuously across the entire spectrum of its activities to improve performance through business focused services, respond to changes in global business conditions and organizational strategies, and to perform quality work in a competitive commercial environment with complete integrity in business relations with customers and suppliers (French \& Bell, 1978).

One of the critical success factors in putting these aims into practice is the continuing development of the workforce with required mix of business managerial and specialist skills that are capable of providing high value services, skills to meet the changing business needs and actively participating in decision- making processes in the management of the organizations business. To make these contributions workers must be provided with the development opportunities which will enable them to continuously improve their performance in their current jobs and at same time to manage their own development in preparation for the ever challenging jobs of tomorrow. Worker also learn a great deal from the experiences of others and as they become competent in one area of work, they will move on to new roles with new responsibilities. With each change they gain valuable knowledge and develop abilities .This situation eventually brings both management and labour closer and fosters long awaited peace and harmony that they both desire for effective efficient performance.

\subsubsection{Systems theory perspective in labour relations}

(Walton and Mekersie 1991) saw labour relations from systems theory perspective to identify the four components namely: Determinants, Areas of interaction and activities Relationships and Consequences. As with all systems, there is a fundamental relationship between the elements whereby they interact to a greater or lesser extent with one another. The relationship between the parties can better be understood in the context of collective bargaining and negotiation of a collective agreement. This specifically applies to the whole lots of interactions between labour and management.

Interaction and activities, deals with the nature of relationships that will facilitate better labour-management relations which can as well help potentially to build more collaboration or consensus between both parties.

It is trite knowledge that the nature of or pattern of relationships between labour and management range is on a continuum, from open conflict at one end to co-operation or consensus at the other (Peil, 1977). Between these two extremes, a number of points can be identified as characteristics of a certain kind of relationship.

In a case of conflict, the relationship is characterized by extreme distrust and dislike of the other party (Otobo, 
1988), in a containment aggression relationship, there is still distrust but not to the same degree, and dislike becomes antagonism. As we move towards accommodation at its centre, the relationship becomes more courteous, and there is limited trust and acceptance of the other party.

To progress further on the continuum, the experience suggests that the parties must pass through a transitional phase before they are able to function in a truly consensus model.

The transitional phase is characterized by experimentation in which the parties search out and test new ways of working together around issues and problems of common concern. Obviously such risk-taking required a degree of trust and openness that is not characteristic of only traditional adversarial behaviour. It should be stressed that organizations that attempt to jump from one end of the spectrum to the other, without passing through such interim stages are likely doomed to failure (Walton \& McRersie 1991). Collaboration and consensus is the final stage and it involves a very positive relationship between the parties, trust and acceptance of the legitimacy of each others role and responsibilities and a conscious striving for mutually satisfying solutions to problems within the context of a collective bargaining relationship and subsequent consensus. According to proponents of the system perspective in explaining labour relations, consequences represents among others, productivity, industrial peace and development etc.

\subsubsection{Consensus blending model with a blend of behaviours}

In as much as conflict remains a permanent feature in labour-management relations, consensus building of both parties will as a new trend minimize the occurrence of conflicts. But to eradicate conflicts and strikes completely is a mission impossible. It is for this genuine reason that a new modeling approach that tends to blend accommodation, collaborating, and compromising is adapted from the works of (Thomas Kilmann, 1974, Walton \& Mekersie,1991; Mitchell, 2002 \& Akanji, 2010) towards insitutionalising consensus building behaviour that will help result to industrial peace and harmony. This is a new model towards consensus building which advocates for a blending of the three conflict-handling approaches as indicated in the schematic diagram figure 2.

The model which is a schematic representation of three parts of consensus building behaviour namely, the work environment as the input which consist of labour and management, the second part, as the process consist of conflict and the conflict handling approaches, accommodating, collaborating and compromising and the output/outcome, which include consensus agreement, industrial peace and harmony, high productivity level, motivation, job satisfaction etc.

In the work environment, labour-management relation is characterized by conflict of interests. Conflict is unavoidable in industry and there must be peace for work activities, growth and development to strive. For this reason conflict management approaches are designed to handle conflicting issues of interest that strain labour management relations. These approaches are accommodating, collaborating and compromising. These are possible alternative conflict management approaches. The blending and adaptation of these three will result to effective labour management relations. In the process, accommodating and collaborating approaches will blend to have accommodating-collaborating conflict management; collaborating and compromising approaches blend to have collaborating - compromising conflict management while the blending of accommodating and compromising approaches will result to accommodating - compromising conflict management. Each blend is a combination of the characteristics of the other approach to produce more effective results. The outcome of such an arrangement will include effective consensus, rapid industrial peace and harmony, efficient and effective productive level, sufficient motivation, job satisfaction, adequate employee welfare and so on.

\subsubsection{Conflictual nature of employment}

Relationship: This section focuses on those substantive areas of labour management relations which often result to conflicts. Adejumo (2011), tracing causes of conflict between employers and employees listed the causal factors to include wages, job security, workplace health and environment, union relations, government policy, company policy and the economic factors which include ineffective communication, breach of contracts, benefits, allowances and other emoluments.

Issues relating to wages and Salary Administration as well as fringe Benefits: The relationship between the employer and the employee centers on implicit contract. This is an agreement between unequal parties in which the employee in the light of his or her particular motives, expectations and interests, attempts to make the best deal possible given his or her personal resources such as skill, knowledge, physique, wealth etc. The bargain which is strict involves a certain relationship in part explicit but largely, owing to its indeterminacy implicit between the employee inputs of effort, impairment and surrender of autonomy and employee rewards of cash payment and fringe benefit such as job satisfactions, social rewards, security, power, status, career potentials etc. Whenever a 
particular implicit contract is perceived to go out of balance, the grievance may lead to any of a range of employee reaction from striking to absenteeism and from obstructive behavior to resigning etc.

Controversy over the legitimacy of the existence of the trade union in work Organisations: Fox (1972) points out that the unitary framework offers a variety of ways of questioning the legitimacy of trade union activities suggesting, alternatively that unions are historical carry over that is no longer needed in an age of enlightened management, that they are outcomes of sectional greed or that they are vehicles for subversive political interests.

Since unions exist conflict then is inevitable but management and unions should be left to settle their differences, as far as this is possible, on their own terms (Donovan, 1978).

Unstable bargain between the worker and the employer due to market context: market context as an environmental factor renders most collective bargain inoperative and unstable. Market 'viability' on the part of the employer creates a constant pressure to minimize cost - This leads to the pressure to either cut the rewards or increase the efforts of the employee. In either way it is to the employees' disadvantage. However, the employees are bound to defend themselves, especially since they buy goods and services in the same market.

The following are ways that proper solutions to conflictual labour management relations can be made:

- Institutionalization of conflict, example shifting from making use of a high informal understandings and accommodations in the workplace to formal collective bargaining arrangements.

- Managerial and labour involvement in conflict legislation such as collective agreement.

- Organizational employment strategies devoid of corruption.

- The role of the state using its agencies to reform or modify the subsystems that deals with tensions and conflicts among others. When such an implicit understanding begins to show light, it then follows that consensus between both partners is visible and realistic.

This paper considers the consensus theory perspective, lifted from the field of sociology and the Thomas Kilmann (1974) conflict model instrument as bases of frameworks.

\subsection{Supporting evidence}

The consensus building approach to decision making has a wide application. These include resolution of neighborhood and environmental dispute, settlement of community disputes, Joint venture among businesses, Promoting civic participation and involvement in the well-being of a community, and in the resolution of industrial disputes etc. The 1970 riot in Rochester, New York schools as reported by Shearouse (1993) is a good example of consensus decision making in practice. The coalition FIGHT of 58 blacks minority did not want voting in resolving the issue because of an imminent lose-win situation and fear of domination by the white majority. They agreed on a mediator who suggested consensus decision making as the way out and it was adopted. "Safety in schools" was also adopted as the shared definition of the problems, and by so doing were able to work through their differences.

Unsoeld (1988) in his article "Hawaii water wars" reported how a hellish dispute over a scarce resource was resolved by a council woman, JoAnn Yukmura as mediator. The dispute arose following the constitutional provision requiring Hawaii's state legislature to protect, control, and manage the state's surface and ground water. For almost a decade and as a result of pressure from the various interest groups, the law makers were unable to adopt a state water code. The problem was eventually resolved following consensus decision making process code named "water code Roundtable" The result of the mediation was a 75 page agreement which included the establishment of an independent water agency and an enactment of a system of water use permits.

\subsubsection{Oil subsidy removal in Nigeria}

The one week strike in Nigeria embarked upon by the Nigerian labour congress (NLC) and the Trade Union congress (TUC) supported by some civil society organisations over the removal of subsidy on premium motor spirit (PMS) or petrol is a classical case of government unilateral action rather than consensus building. The organized labour and civil societies described government action of increasing pump price from 65 naira to 148 naira and latter 97 naira as unilateral. The worst case scenario would have been a compromise, where labour would have had a say in the decision to peg the pump rice at 97 naira. The issue of oil subsidy as it is presently is a time bomb and a postponement of the evil day.

The governmental action can easily be explained by the Marxist ideology that the executive of the modern state is but a committee for managing the common affairs of the whole Bourgeoisie. (Marx \& Engles, 1958; Noah, Y.(2009). The government suppressed labour by the deployment of troops to disperse an otherwise peaceful 
protest instead of consensus.

\section{Consensus building methodology}

The aim and objective of this paper is to examine theoretically the need for consensus building as a tool or strategy that guarantees industrial peace and harmony. To achieve these objective authors employed desk research method that made great use of literature materials from text books, relevant journal articles, newspaper publications, excerpts from papers, internet source among others.

Consensus building as a decision making process incorporates the basic elements of decision analysis method, which includes problem definition or statement of the problem, Model specification, data collection and model verification, evaluation of the consequences of each alternative action based on certain criteria and finally making a choice of the preferred alternative. Since the study is theoretical in nature, the consensus building process has been presented in the generic form using Barbara Gray's version. However, evidence from current literature support the consensus building model on which conclusions and policy recommendations are made.

According to Barbara Gray (1989) the methodology of consensus building as a decision making process is in three phases: problem setting phase, direction phase and the implementation phase. During problem setting phase, the parties must: (1) arrive at a shared definition of the problem, including how it relates to the interdependence of the various stakeholders; 2) the parties must make a commitment to collaborate; 3) other stakeholders must be identified whose involvement may be necessary for the success of the endeavour; 4) the parties must acknowledge and accept the legitimacy of the other participants; 5) the parties must decide what type of convener or leader can bring the parties together; and 6) the parties must determine what resources are needed for the collaboration to proceed.

The direction-setting phase is characterized by six essential steps: 1) establishing ground rules; 2) setting the agenda; 3 ) organizing subgroups (especially if the number of issues to be discussed is large or the number of stakeholders exceeds the twelve- to-fifteen-member limit for effective group functioning); 4) undertaking a joint information search to establish and consider the essential facts of the issue involved; 5) exploring the pros and cons of various alternatives; and 6) reaching agreement and settling for a course of action.

The implementation phase involves 1) participating groups or organizations deal with their constituencies; 2) parties garner the support of those who will be charged with implementing the agreement; 3) structures for implementation are established; and finally 4) the agreement is monitored and compliance is ensured.

The fifteen steps in Barbara Grey's model for consensus building implementation may not be followed rigidly and sequentially. The number of steps adopted for any project will depend on the project size, the level of risk and availability of funds among other factors.

There are differing opinions as to the role of consensus in collaborative endeavour. Consensus does not actually lead to agreement on all issues, but rather evolves as participants redefine their terms in accordance with their mutual interests and goals. Consensus emerges when the stakeholders agree that they can live with the proposed solution even though it is not the preferred solution.

\section{Implications for labour-management relations}

The organization is 'a small-society' and a social system with members who join together to achieve common goals. Interestingly, what happens in the larger society also happens at a micro-level in the 'small-society' called organization.

The members of the work organization are the workers. Jointly, they carry out daily activities which are governed by set of rules, procedures and regulations. These rules or procedures including their values, expectations, motives, understanding and ways of thinking which are as old as the organization are through the process of socialization internalized in the life and behaviour of these workers in their day-to-day activities in the organization. These internalized rules are passed on to the new entrants or employees as organization culture which constitute the correct mode of conduct. The workers conformity to rules and procedures imply that they are in agreement with the organizational culture, as workers will conform to acts or behaviour considered to be appropriate and disagree with those considered inappropriate. Conflict is considered as inappropriate act and is an aberration from the consensus perspective. But the labour-management relation is rooted in conflict.

The consensus perspectives believe that there is no structural conflict making divisions in labour-management relations. For the theorist, conflict cannot be endemic, but a misnomer that creates the room or pave the way for consensus building.

In as much as conflict remains a permanent feature in labour-management relations, consensus building of both 
parties will as a new trend minimize the occurrence of conflicts in their interaction and relationship with each other. But to eradicate conflicts and strikes completely out of their relationship is a mission impossible, for that is the goal of consensus theorist -a conflict and strike-free economy which is not possible. Though conflict and strikes cannot be completely eradicated in a work environment, consensus building enables the stakeholders to transcend and work through their differences towards successful achievement of organizational goals and objectives.

\section{Conclusions}

Man is conflictual by nature and by orientation is bound to express such in collectivity like the work situation. The way in which labour relates with management is very diverse, but it is obvious that the only possible way to enhance a co-operative labour-management relation is to institutionalize consensus as a veritable tool for solving imminent problems that do constantly beset both parties. Such an attempt will minimize or reduce frequent occurrence of conflicts or strikes in the work organization as well as encourage industrial peace and harmony which are necessary ingredients for improved productivity and effectiveness. But it sounds utopian to think of a conflict-free economy rather both parties can make room for conflict accommodation, by so doing reducing its occurrence to a manageable level.

Even so when conflict rears its head in the work organization the fifteen step consensus building process will automatically be activated for conflict resolution. The outcomes of the consensus process will include better decisions, better implementation and better group relationships.

From the problem analysis of labour management relations in general and Nigeria in particular it is clear that the problems can only be efficiently and effectively resolved through the adoption and implementation of the consensus building method. The supporting evidences in the paper buttress this argument.

\section{References}

Achike, O. (1972). Nigerian Law of Contract. Enugu: Nwanife Publishers Limited.

Adejumo, B. (2011). Lab our. In V. Animal- Young. Stakeholders seek way-out of industrial unrest in workplace. Vanguard Newspaper, December 8, pp 12, 26.

Akanji, A.B. (2010). Psycho-Social Factors as Determinants of Conflicting- Handling Behaviour of Labour Leaders and Management Representatives in Work Organisations in Lagos State Nigeria. PhD Thesis, university of Ibadan. pp22-27.

Akanji, R.B. (2010). Psycho- Social Factors as Determinants of conflict- handling behavior of labour Leaders and management representatives in work organizations in Lagos state Nigeria. Ph.D. Thesis submitted to the university of Lagos.

Alexander, M. (1978). Organization Development: A Behavioural Approach. Personnel Review, (7), 4, P 17-23.

Beach, D.S. (1975). Personnel: The Management of People at Work. New York Collier: Macmillan International Edition.

Fajana, S. (2006). Industrial Relations in Nigeria: Theory \& Features. Lagos: Labofin and Company.

Fench, W.D., and C Bell Jr. (1978). Organizational development ( $2^{\text {nd }}$ ed.). Englewood Cliffs NJ: Prentice Hall.

Fox, A. (1972). A Sociology of work in industry Themes \& Issues in Modern Sociology. London: Collier MacMillan.

Gray, B. (1989). Collaborating: Finding Common Ground for Multiparty problems. Jossey Bass Business and Management Series, Michigan.

Haralambos, M. (1980). Sociology: Themes and Issues, Pp 11-12.

Kay, S.D., and Paul, J.T. (1976). Labour-Management Alliances: The Case of Alberta Power Limited. Human Resource Planning, vol. 19: Pp 1-2.

London, S. (2012). Collaboration and Community. [Online] Available: http://www.scottlondon.com/reports/ppcc.html

Marx, K., and Engels, F. (1958). Selected works. Moscow. Foreign Language Pub. House.

Noah, Y. (2009). Democratisation process and Industrial Relations Practice in Nigeria. [Online] Available: http://www.unilorin.edu.ng/publications/democratics.htm (Jan. 24, 2012)

Obisi, C. (1996). Labour Relations in Nigeria. Ibadan: Jackbod Enterprises.

Otobo, D. (1988). State and Industrial Relations in Nigeria Lagos and London. Malthouse Publishing Limited. 
Peil, M. (1997). consensus and Conflict in African Societies. An introduction to Sociology. Longman group limited.

Shearouse, S. (1993). A Vote for Consensus. MCS Conciliation Quarterly, Fall Pp 2-3. [Online] Available: http://www.crinfo/dx.doi.org/articlesummary/10540/

Unsoeld, U. (1988). Hawaii's Water Wars: A Pacific Paradise Settles a Hellish Dispute Over a Scarce Resource. Consensus. Public Disputes Network. November. No.1. Pp. 1, 8.

Walton, R., \& Mckersie, R. (1991). Behavioral Theory of Labour Negotiations (2 ${ }^{\text {nd }}$ ed.). Ithaca. NY: ILR Press.

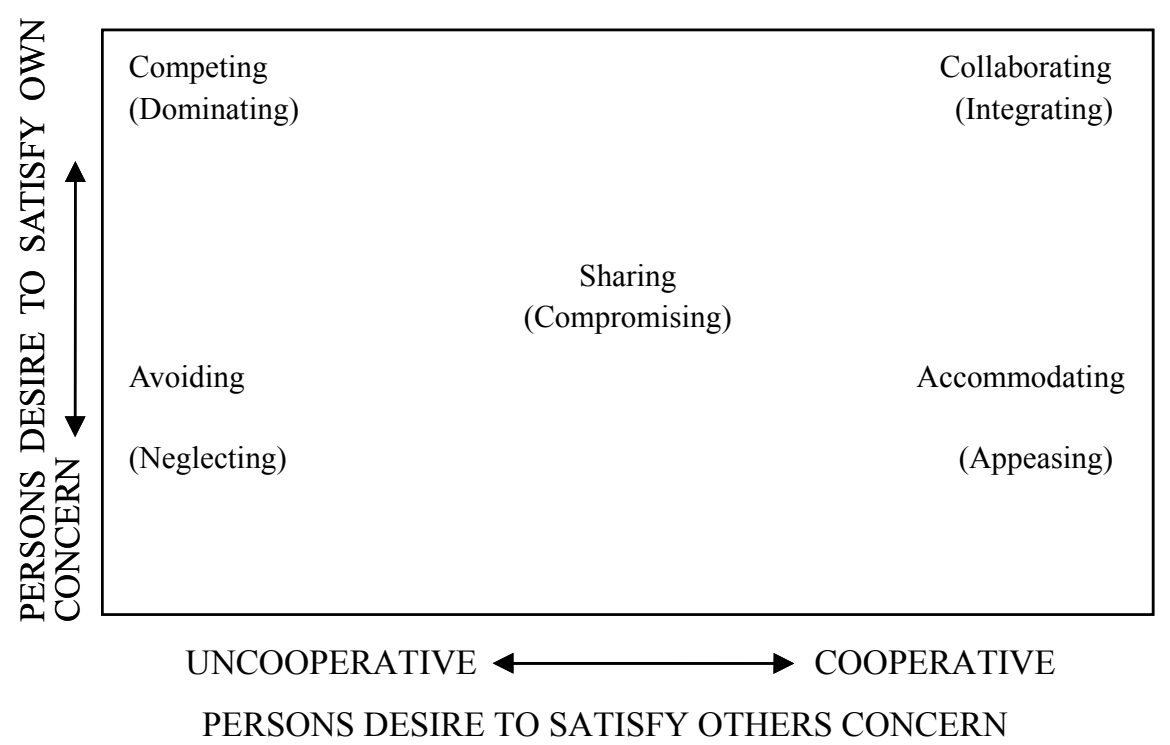

Figure 1. Thomas - Kilmann conflict - handling behaviour model

Source: Adopted from Michell,R.C. (2001). Psychosocial determinants of conflict-handling behavior of workers. [Online] Available: www.academicjournals.org:/err/pdf/pd.doi.



Figure 2. Consensus building model with a blend of behaviours

Source: Adapted from the works of (Thomas Kilmann, 1974, Walton \& Mekersie, 1991; Mitchell, 2002 \& Akanji, 2010). 